of whom eventually called for his ousting. On 9 July, in the midst of a special assessment of his performance, Proenza was placed on leave.

Last week, he got his chance to tell his side of the story in Washington DC, to the House Committee on Science and Technology. Democrats on the committee pressed the question of whether Proenza had been sidelined because of his whistleblower activities on QuikSCAT. Meanwhile, Republicans griped about the committee spending its time investigating what they dismiss as a routine personnel matter.

Nick Lampson (Democrat, Texas), who chaired the hearing, got at least one thing right. "The only storms the centre should be dealing with are those that form out in the ocean," he said. At the hearing, both sides acquitted themselves well: Proenza delivered an impassioned defence of his leadership, and Conrad Lautenbacher, NOAA's administrator, gave a lengthy and reasonably convincing explanation of why the agency felt it had to remove Proenza from his position.

The Proenza affair is not something that hurricane researchers and forecasters really need at this point, as the storm season begins to gear up. Government agencies are still reeling from their failure to cope with Hurricane Katrina in 2005, and scientists are dealing with the fall-out from their very public spats over the possible link between hurricanes and global warming (see Nature 441, 564-566; 2006).

So NOAA needs to show coherent and firm management. First, it should find a relatively quiet spot to assign Proenza to - outside of the hurricane centre, where employee resentment is apparently too high for him to continue to function as an effective leader.

Lautenbacher is aware of the need for NOAA to raise its public profile and assert itself as a powerful scientific agency, rather than just a backwater of the Department of Commerce, of which it is part.

But it must make sure that its public-relations efforts don't get in the way of its scientific work. The very existence of a multimillion-dollar anniversary celebration is a cause for concern. And NOAA scientists have also been unhappy in recent months about management decrees suggesting, for example, that they improve the agency's branding by substituting 'NOAA' for 'National' in the names of centres such as the National Weather Service and the National Hurricane Center. Both of these outfits have distinguished histories and identities of their own, and NOAA needs to find ways of asserting itself and its mission in the public eye without diminishing them.

More substantively, the agency needs to address gaps in its satellite systems. Proenza is only the latest to highlight these. The National Academies had already done so, most recently in January, when it set out a national strategy of Earth-observing missions for the federal

"Spats among staff should not distract from the larger task of focusing Earthobservation priorities." government. That plan would include an ocean-winds mission to do much the same job as QuikSCAT. An area of further concern was, the academies said, the level of coordination between NASA, which has customarily developed research satellites, and NOAA, which takes them into operational use.

NOAA needs to make sure that spats among staff at its hurricane centre do not distract from the larger task of focusing Earth-observation priorities in the coming decades. Researchers have already clarified what they need. Now it's time for the government to follow those recommendations and make sure the next generation of satellites is in place for the storms yet to come.

\section{California dreaming}

\section{Universities should draw the line at certain types of support from the drug industry.}

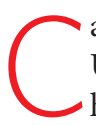

alifornia, home to the largest public university system in the United States, is currently a battleground in a struggle over how to police perceived conflicts of interest at its medical schools. The university's campuses are trying to derail a proposal from its central administration that would clamp down on common drug-industry practices, such as the sponsorship of free lunches for medical students and the granting of general purpose, 'unrestricted' money to some faculty members (see page 394 ).

The campuses argue, for example, that these unrestricted grants can provide important sources of revenue. And some faculty members are also questioning the need for the policy. On behalf of a committee at the University of California, Los Angeles, for instance, Hossein Ziai writes: "With all the myriad problems facing health care in the United States...this issue seems rather trivial in comparison, and we question whether there is any demonstrable harm (as opposed to perceived harm) arising from these practices." The campuses' concerns about their autonomy, and freedom of action for their staff, deserve careful consideration.

But these arguments fall flat against the growing evidence that some forms of support from drug companies can taint perspectives and practices. Policy analysts such as Lisa Bero at the University of California, San Francisco, have documented how pervasively industrial funding can influence the outcomes of studies, and have shown the inadequacy of measures meant to address these influences, such as disclosure of funding sources. Additionally, one source of the well documented problems of the US healthcare system is the large amount of money spent by pharmaceutical and medical-device vendors on marketing efforts, including some of the types of activity that would be banned under the University of California's proposed policy.

On both ethical and rational grounds the university's policy is worthy of general support. But, as with most things, the broader issue here is a fiscal one. In 2004, the University of California's president, Robert Dynes, signed a deal with Governor Arnold Schwarzenegger that froze state public funding of the university's system, began tuition and fee hikes, and committed the university to seek billions of dollars a year in additional private-sector funding.

In a sense, the latest policy tries to put the brakes on a trend towards heavier reliance on private funding that this fiscal squeeze has unleashed. The university's campuses are understandably concerned about their ability to attract funding from all sources so that they can continue to operate at world-class levels. The best course available to them, nonetheless, is to follow the high standards that have recently been set at other academic medical centres, such as those at Stanford University, and to embrace the proposed policy. 